\title{
Crystallinity as New Toughening Concept for Epoxy Resins: Influence of Branching of Integrated Polyester
}

\author{
Arne Straßburg, Hendrik Lützen and Andreas Hartwig* \\ *Fraunhofer Institute for Manufacturing Technology and Advanced Materials (IFAM), \\ Wiener Straße 12, D-28359 Bremen, Germany \\ Tel: +49-421-2246-470, Fax: +49-421-2246-430, E-mail: andreas.hartwig@ifam.fraunhofer.de
}

\begin{abstract}
Epoxy resins typically applied for structural adhesives were toughened by poly( $\varepsilon$-caprolactones) (PCL) with different degree of branching. These PCL have the same molar mass and each arm is terminated with a hydroxyl group. The PCL were integrated into the epoxy network formed during the thermally induced cationic polymerization of a cycloaliphatic epoxy resin by the activated monomer mechanism. The PCL form domains covalently bound to the epoxy network and domain size decreases with increasing branching of the PCL. Interestingly the domains show characteristics from amorphous as well as crystalline behavior. Toughness of the formed epoxy resins increase with decreasing size of the domains in other words increasing degree of PCL branching.
\end{abstract}

Key words : epoxy resin/morphology/crystallinity/segregation/polycaprolactone

(Received : December 23, 2014)

\section{Introduction}

Natural and artificial materials with superior properties are all heterogeneous ${ }^{11}$. Natural polymeric materials usually contain crystalline phases and it is the question how to use such a biomimetic concept in adhesives, especially epoxy based adhesives. If not modified, epoxy resins are brittle highly cross-linked polymers. Toughening is usually carried out by the formation of a multiphase material. Most often demixing of a dissolved rubber component takes place during cure leading to the formation of rubber domains covalently connected to the epoxy network. But also nanoparticles ${ }^{2,3}$ and hyperbranched polymers ${ }^{4)}$ are under continuous examination for epoxy toughening. Especially for high performance epoxy resins toughening is carried out by engineering thermoplastics like polysulfones. If photochemically or thermally induced cationic curing of epoxy resins is carried out toughening is usually realized by the integration of polymeric alcohols into the polymer network by the so called activated monomer mechanism ${ }^{5 \sim 8)}$. A major drawback of this method is that basically the polymer softens combined with a reduction of the glass transition temperature, besides the desired toughening of the material. Some years ago it was found that it is possible to overcome this disadvantage by the incorporation of the crystalline polyether diole poly(tetrahydrofurane). In fact tough and even rubber elastic cured epoxy resins were formed. Unfortunately, the polymers have poor thermal stability and emit tetrahydrofuran caused by chain cleavage in the presence of superacid used as the polymerization catalyst ${ }^{9}$. To overcome this limited thermal stability telechelic crystalline polyester diols, namely poly( $\varepsilon$-caprolactone) of different molar mass, were used as alternative. By this modification a heterogeneous morphology could be detected ${ }^{10)}$ which can be controlled by nucleation during formation of crystalline PCL domains ${ }^{11)}$ and the resulting polymers have high fracture toughness. Thermosetting polymers with crystalline domains were formed and their applicability as adhesives ${ }^{12)}$ or shape memory polymers ${ }^{13)}$ could be 
demonstrated as well as improvements of the mechanical properties of flax fiber reinforced epoxy resin ${ }^{14)}$. The experiments were carried out with diols and it is the question what the influence of functionality and branching of the telechelic PCL on the resulting properties of the cured epoxy resin containing these different PCL is. In the work presented here PCL are prepared by ring opening polymerization of $\varepsilon$-caprolactone with start alcohols of the same number of $\mathrm{OH}$-groups as desired for the final PCL. The mean molar mass of the PCL is determined by the relation between the amount of alcohol and $\varepsilon$-caprolactone. This was demonstrated for numerous different start alcohols and recently Bilgin et al. showed this for octa-armed PCL with a phthalocyanine core as octafunctional start alcohol ${ }^{15)}$. In the work presented here we show the preparation of PCL with a mean molar mass Mn of $12,000 \mathrm{~g} / \mathrm{mole}$ and functionalities between 1 and 16 on the properties of the cationically cross-linked epoxy resin with the covalently integrated PCL.

\section{Experimental}

\subsection{Materials}

All used compounds were purchased at Sigma-Aldrich (Steinheim, Germany) if not mentioned otherwise. The solvents toluene and acetone were dried over $4 \AA$ molecular sieve. $\varepsilon$-caprolactone was dried over calcium hydride and then distilled in vacuum $\left(5 \mathrm{mbar}, 75^{\circ} \mathrm{C}\right)$. The dendritic polyol blends Boltorn P 1000 and Boltorn P 500 are from Perstorp (Perstorp, Sweden). All start alcohols were used without further purification. The cycloaliphatic epoxy resin 3,4-epoxycyclohexyl-3',4'epoxycyclohexane carboxylate was Omnilane OC1005 from IGM resins (Krefeld, Germany) and the thermally latent initiator benzyltetrahydrothiophenium hexafluoroantimonate was prepared according to the literature ${ }^{16)}$.

\subsection{Characterization methods}

\subsubsection{Size exclusion chromatography (SEC)}

SEC of the prepared PCL was carried out by Polymer Standards Service GmbH (Mainz Germany) with polystyrene calibration at $23^{\circ} \mathrm{C}$ and $\mathrm{THF}$ as solvent. PCL concentration was $5.0 \mathrm{~g} / \mathrm{L}$ and a flow rate of 1.0 $\mathrm{mL} / \mathrm{min}$ was applied. Separation was carried out with PSS SDV columns (PSS pre-column SDV $5 \mu \mathrm{m}, 1000 \mathrm{~A}$; PSS SDV $5 \mu \mathrm{m}, 50 \AA$ A; PSS SDV $5 \mu \mathrm{m}, 100 \AA$; PSS SDV
$5 \mu \mathrm{m}, 1000 \AA$; size each $8 \mathrm{~mm}$ x $300 \mathrm{~mm}$ ) using a Shodex RI 71 differential refraction detector.

\subsubsection{NMR}

${ }^{1} \mathrm{H}-\mathrm{NMR}$ spectra were recorded with a DPX-200 Advance from Bruker (Karlsruhe, Germany) with tetramethylsilane as external standard and $\mathrm{CDCl}_{3}$ as solvent. Molar mass of the different PCL was determined according to Möller et al. ${ }^{17)}$ First the number of caprolactone (CL) units per molecule was determined by the relation of $\mathrm{CH}_{2}$ near an ester group $(\delta=4.05)$ and near an hydroxyl end group $(\delta=3.58-3.74)$. The number of hydroxyl groups is taken for this into account, too. From the number of CL units, the molar mass of CL and the molar mass of the start alcohol the mean molar mass of the PCL was calculated.

2.2.3 Differential scanning calorimetry (DSC)

DSC was performed with a TA Instruments 2920 MDSC V2.6 A for the characterization of the prepared PCL. The following temperature program was used: heating from $20^{\circ} \mathrm{C}$ to $100^{\circ} \mathrm{C}$ with $10 \mathrm{~K} / \mathrm{min}, 5 \mathrm{~min}$ isothermal at $100^{\circ} \mathrm{C}$, cooling to $0{ }^{\circ} \mathrm{C}$ with $10 \mathrm{~K} / \mathrm{min}$, isothermal for $5 \mathrm{~min}$ and heating again to $100^{\circ} \mathrm{C}$ with $10 \mathrm{~K} /$ min. For evaluation of the melting behavior the second heating run was used and for crystallization the cooling run. The degree of crystallization was determined from the melting enthalpy using the melting enthalpy of $135.7 \mathrm{~J} / \mathrm{g}$ for $100 \%$ crystallinity from the literature ${ }^{18)}$.

2.2.4 Dynamic mechanical analysis (DMA)

DMA was carried out with a DMA 2980 from TA Instruments with a heating rate of $2 \mathrm{~K} / \mathrm{min}$ in a temperature range between $-50^{\circ} \mathrm{C}$ and $+230^{\circ} \mathrm{C}$.

\subsubsection{Stress-Strain measurement}

The measurements were carried out with a ZwickZ050 tensile testing machine at $23^{\circ} \mathrm{C}$ and a testing speed of $1 \mathrm{~mm} / \mathrm{min}$. The sample dimensions were according to DIN EN ISO 527 part 1 and 2 form 1BA.

2.2.6 Scanning transmission electron microscopy (STEM)

The samples of cured epoxy resins were cut with a Leica Ultracut UCT under cryo conditions (thickness about $100 \mathrm{~nm}$ ). Staining was carried out with a $2 \%$ aqueous solution of phosphoric tungstic acid for $1 \mathrm{~h}$. STEM was performed with a FEI Tecnai F-20 S-TWIN (Hillsboro, Oregon, USA). The measurements were carried out at $200 \mathrm{kV}$ with a spatial resolution of $1 \mathrm{~nm}$. Images were taken in HAADF STEM mode. 


\subsection{Syntheses and sample preparation}

2.3.1 Synthesis of poly( $\varepsilon$-caprolactone) with different number of alcohol groups and degree of branching

The start alcohol and $\varepsilon$-caprolactone were placed together with $2 \mathrm{ml}$ toluene in a two-necked round bottom flask as given in Table 1. Preparation was carried out in nitrogen atmosphere with continuous magnetic stirring. After $1 \mathrm{~h}$ heating at $110^{\circ} \mathrm{C} 0.019 \mathrm{~g}$ of the catalyst $\mathrm{SnCl}_{2}$ was added and polymerization was carried out at $110^{\circ} \mathrm{C}$ in additional $23.5 \mathrm{~h}$. The toluene was removed in vacuum and the polymerization completed in $2.5 \mathrm{~h}$ at $180^{\circ} \mathrm{C}$ while distilling off residual toluene and monomer. The relation of starting alcohol and $\varepsilon$ caprolactone was chosen in a way that the target molar mass of the polymer should be 12,000 g/mole.

2.3.2 Cationic polymerization of the epoxy resin with the different PCL

1 wt.- $\%$ benzyltetrahydrothiophenium hexafluoroantimonate was dissolved in 3,4-epoxycyclohexylmethy 1-3',4'-epoxycyclohexane carboxylate. The different PCL were added, so that mixtures containing 13, 23 or $31 \mathrm{wt}-\%$ PCL were formed. The compounds were mixed with magnetic stirring at $75^{\circ} \mathrm{C}$ for $40 \mathrm{~min}$. The samples were poured into aluminum molds (thickness of the plates $4 \mathrm{~mm}$ for DMA and $3 \mathrm{~mm}$ for stress-strain measurements) impregnated with the release agent ACMOScoat 82-6007 (ACMOS, Bremen, Germany) and cured $60 \mathrm{~min}$ at $110^{\circ} \mathrm{C}$ followed by $60 \mathrm{~min}$ at $125^{\circ} \mathrm{C}$ and
30 min at $145^{\circ} \mathrm{C}$. After cooling samples for the different characterization methods were cut by water jet cutting.

\section{Results and discussion}

3.1 Synthesis and properties of poly $(\varepsilon$-caprolactones) with varying branching and number of OH-groups

The PCL were prepared by the tin catalyzed ring opening polymerization of $\varepsilon$-caprolactone with different start alcohols having between 1 and 16 hydroxyl groups. A PCL arm grows from each of the $\mathrm{OH}-$ groups, in other words PCL with different degree of branching bearing an OH-group at the end of each arm were formed. The reaction is shown in Fig. 1. The relation of start alcohol and monomer was selected in a way that the desired molar mass should be 12,000 $\mathrm{g} /$ mole. This means that with increasing branching the length of the single PCL arms decreases. The different start alcohols are summarized in Table 1 together with the amount of chemicals used for synthesis and the resulting molar masses. The molar masses were determined by GPC with polystyrene calibration as well as by ${ }^{1} \mathrm{H}-\mathrm{NMR}$. The results show that the formed prod-

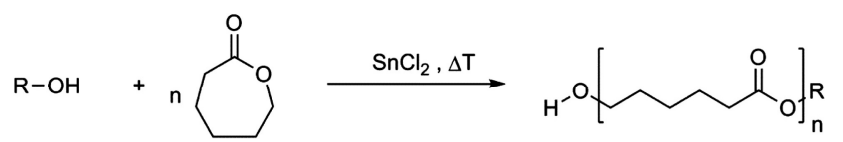

Fig. 1 Tin catalyzed ring opening polymerization of PCL with a start alcohol.

Table 1 Applied starting alcohols and their amount and amount of $\varepsilon$-caprolactone for synthesis of the poly( $\varepsilon$-caprolactone) together with their molar mass determined by ${ }^{1} \mathrm{H}-\mathrm{NMR}$ and GPC.

\begin{tabular}{l|l|l|l|l|l|l}
\hline starting alcohol & $\mathrm{n}_{\mathrm{OH}}$ & $\mathrm{M}_{\text {Alc. }}$ & $\mathrm{m}$ caprol. & $\mathrm{m}$ alcoh. & $\mathrm{M}_{\mathrm{PCL}}(\mathrm{NMR})$ & $\mathrm{M}_{\mathrm{PCL}}(\mathrm{GPC})$ \\
& & {$[\mathrm{g} / \mathrm{mole}]$} & {$[\mathrm{g}]$} & {$[\mathrm{g}]$} & {$[\mathrm{g} / \mathrm{mole}]$} & [g/mole] \\
\hline 1-hexanole & 1 & 102.2 & 59.489 & 0.511 & 10,000 & 13,000 \\
\hline 1.6-hexandiole & 2 & 118.2 & 59.410 & 0.591 & 14,000 & 13,200 \\
\hline glycerine & 3 & 92.1 & 59.539 & 0.460 & 17,000 & 9,000 \\
\hline propane (TMP) & & 134.2 & 59.330 & 0.670 & 10,000 & 10,000 \\
\hline pentaerythritole & 4 & 136.2 & 59.319 & 0.681 & 18,000 & 12,000 \\
\hline dipentaerythritole & 6 & 254.3 & 58.729 & 1.272 & 15,000 & 9,000 \\
\hline Boltorn P 1000 & 14 & 1500 & 52.501 & 7.500 & 6,000 & 5,000 \\
\hline Boltorn P 500 & 16 & 1800 & 51.008 & 9.000 & 7,000 & 8,000 \\
\hline
\end{tabular}




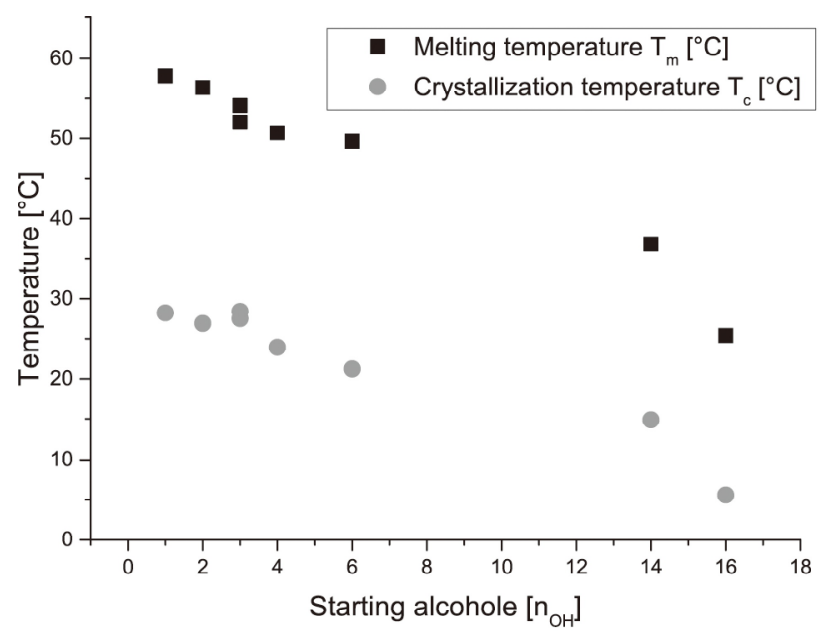

(a)

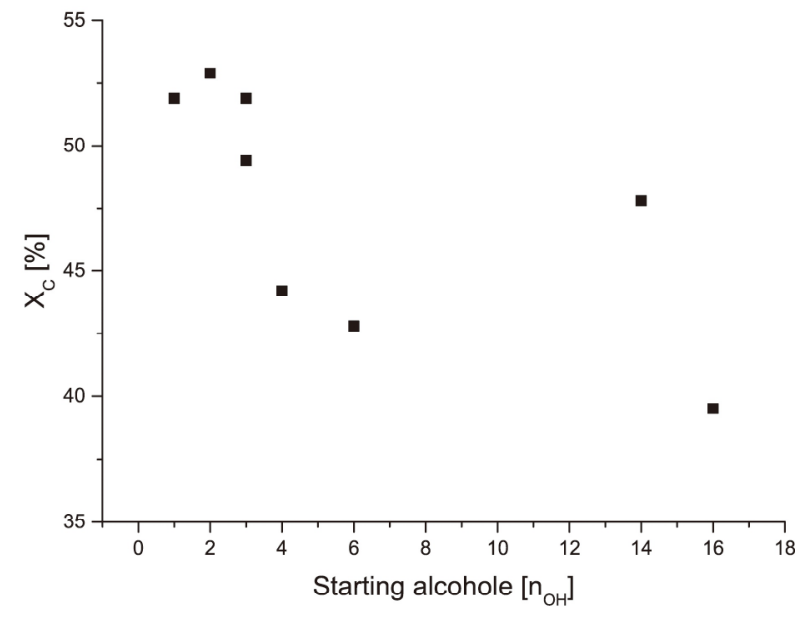

(b)

Fig. 2 Dependence of melting and crystallization temperature (Fig. 2a, left) and the degree of crystallization (Fig. 2b, right) of the prepared PCL on the number of OH-groups per PCL molecule determined by DSC.

ucts have almost the desired molar mass of $12,000 \mathrm{~g} /$ mole. There are some deviations in the results between the two analytical methods but no systematic tendency is visible. The PCL formed with the highly branched start alcohols with $\mathrm{n}_{\mathrm{OH}}=14$ and 16 seem to have a lower molar mass of about 7,000 g/mole determined by both methods. This might be caused by the dense packing of the growing chains restricting the possibilities for polymerization.

PCL is a semi-crystalline polyester. In order to determine the influence of branching of the prepared PCL on the melting and crystallization behavior DSC measurements were carried out. Melting temperature of commercial PCL with a molar mass in the range of $10,000 \mathrm{~g} / \mathrm{mole}$ and two hydroxyl groups is about $55^{\circ} \mathrm{C}$ with a degree of crystallization of about $52 \%{ }^{10)}$. This corresponds well with our findings shown in Fig. 2 (left graph) for $\mathrm{n}_{\mathrm{OH}}=2$. Melting as well as crystallization temperatures decrease almost linearly with increasing branching of the PCL structure. The gap between both is for the complete set of PCL about $30^{\circ} \mathrm{C}$ and the melting temperature decreases from about $55^{\circ} \mathrm{C}$ for $\mathrm{n}_{\mathrm{OH}}=1$ or 2 to about $25^{\circ} \mathrm{C}$ for $\mathrm{n}_{\mathrm{OH}}=16$. The decrease of both temperatures show that the alignment possibility for the single PCL chains into a crystallite decreases with increasing branching as expected. The constant gap between the temperatures indicates that branching does not inhibit the crystallization rate. As the carried out measurements are dynamic experiments, one can conclude that branching does not has an extra kinetic effect on the crystallization process. The findings for the temperatures are confirmed by an almost linear decrease of the degree of crystallinity from about $52 \%$ for $\mathrm{n}_{\mathrm{OH}}=1$ or 2 to about $40 \%$ for $\mathrm{n}_{\mathrm{OH}}$ $=16$ (Fig. 2, right). These findings are in agreement with the work of Choi $^{19)}$ and Binder ${ }^{20)}$ who recently could show that crystallization can be increased if a star shaped PCL is transformed into linear PCL by photocleavage.

\subsection{Influence of PCL-branching on the properties of cationically cured epoxy resins}

If epoxides are polymerized cationically in the presence of alcohols the alcohols are integrated into the polymer network by the activated monomer mechanism. This is often used to make cationically cured epoxy resins less brittle but leads usually just to softening and not the desired toughening. In any case the network density is reduced and this should lead to a decrease of glass transition temperature. The cycloaliphatic epoxy resin was modified with 13, 23 and 31 wt.-\% of the different PCL, respectively. On the one hand $\mathrm{T}_{\mathrm{g}}$ should decrease with increasing amount of the PCL and on the other hand by the increasing number of hydroxyl groups within the PCL molecules. This is shown in Fig. 3 and interestingly $\mathrm{T}_{g}$ is almost constant at $125^{\circ} \mathrm{C}$ for 13 wt.- \% PCL independently on the total hydroxyl amount or the epoxy/OH relation. It seems that the increasing number of hydroxyl groups with increasing degree of PCL branching influence the polymer network to only a limited degree. For the two higher PCL concentrations a strong decrease of $\mathrm{T}_{\mathrm{g}}$ with increasing hydroxyl content is observed. For some of the samples with high PCL content and high number of hydroxyl 


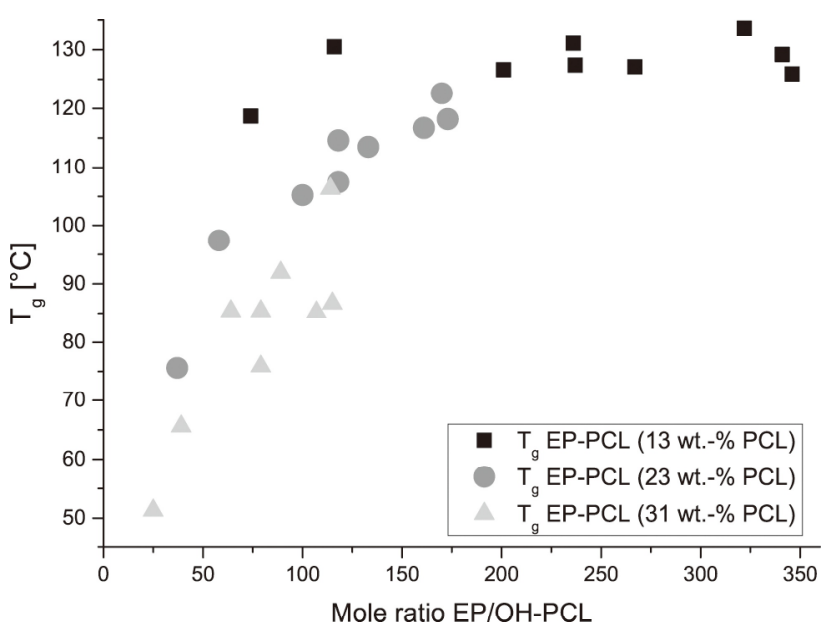

Fig. 3 Influence of the relation between epoxy groups and hydroxyl groups from the PCL on the glass transition temperature of the cured epoxy resins determined by DMA.

groups $\mathrm{T}_{g}$ comes already close to room temperature and should influence the measurement of the stressstrain behavior.

Tensile tests were carried out for all polymers as shown in Fig. 4 a, b and c for the three different PCL concentrations. Elongation at break increases strongly with increasing PCL and $\mathrm{OH}$ content of the samples compared to the pristine epoxy resin. For a lot of samples yield strength increases, too. This combination of concomitantly increasing strength and elasticity is desired for toughening. Especially for the samples with 13 wt.-\% PCL increase of yield strength is pronounced and increases also with the degree of PCL branching. Also for the samples with 23 wt.-\% PCL yield strength increases with increasing PCL branching but it is not as pronounced as for $13 \mathrm{wt} .-\%$ and the strength is on a similar level as that of the epoxy resin but elongation at break is higher by a factor of about 8 . This corresponds also with the decreasing $\mathrm{T}_{\mathrm{g}}$ as shown in Fig. 3 and is confirmed by the samples containing $31 \mathrm{wt.-} \%$ PCL. These samples are highly elastic but yield strength decreases with increasing PCL branching or in other words decreasing $T_{g}$. The results show that epoxide modification with the crystalline PCL leads to an increase of yield strength and toughness as long as $\mathrm{T}_{\mathrm{g}}$ is well above the testing temperature. If an increasing $\mathrm{OH}$-content leads to a decreasing network density and decreasing $\mathrm{T}_{\mathrm{g}}$ this leads to a still increasing elasticity but yield strength decreases.

It is the question if the tensile properties also depend on the morphology of the polymers. Fig. 5 shows

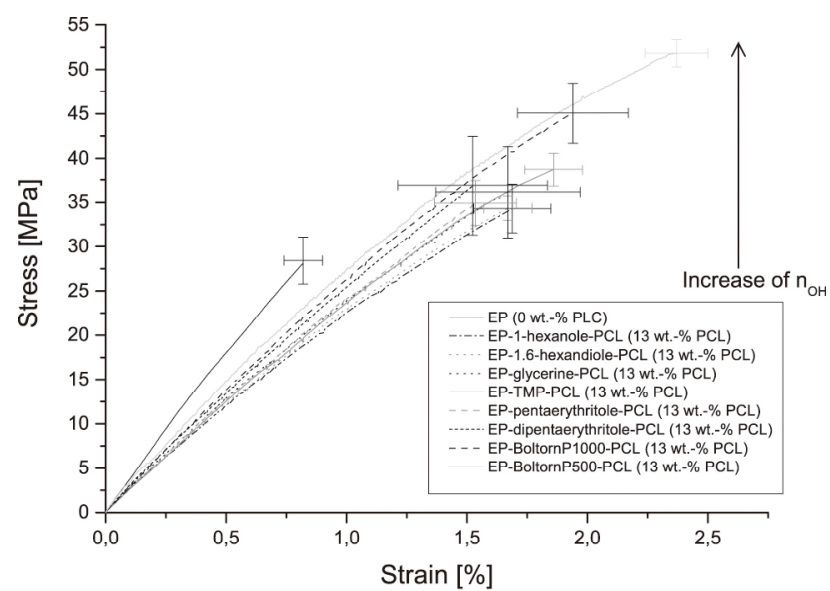

(a)

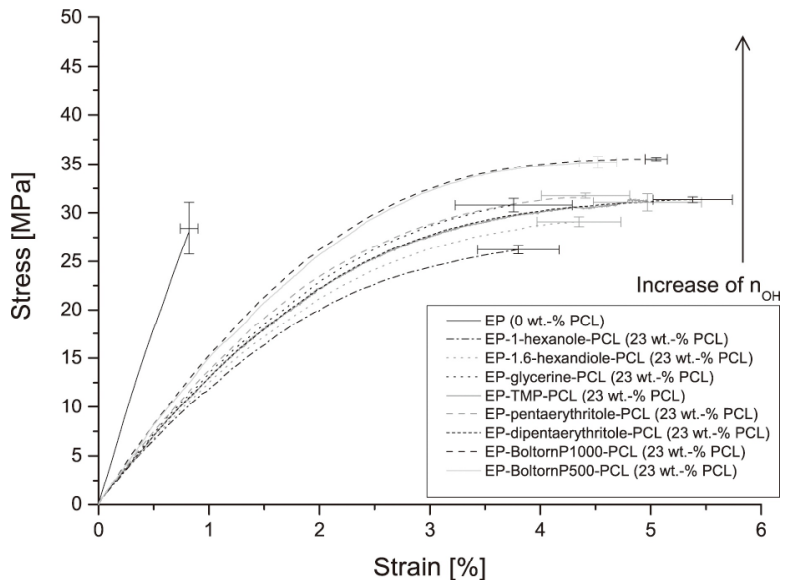

(b)

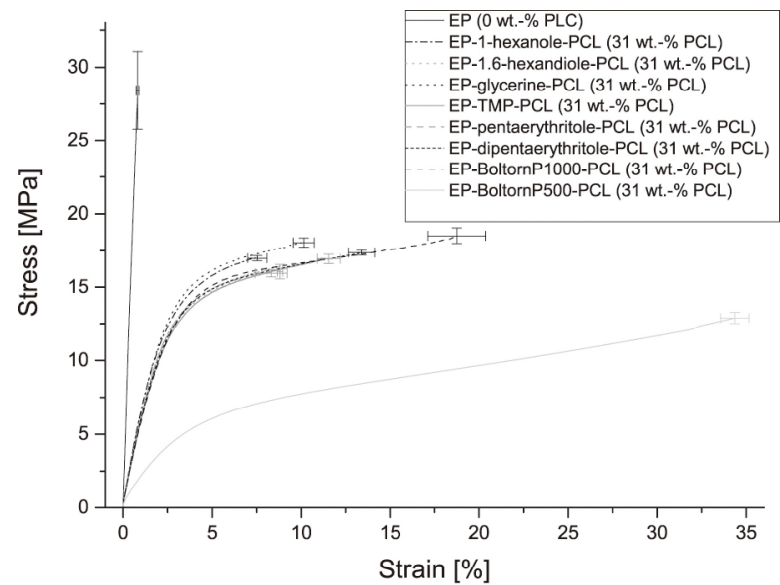

(c)

Fig. 4 Stress-strain curves of the cured epoxy resins modified with 13 (up), 23 (middle) and 31 wt.-\% (down) of the differently branched PCL.

STEM images in two different magnifications illustrating the influence of branching on the formed morphology. Interestingly in neither sample spherical structures are observed as it is e.g. typical for rubber demixing during epoxide cure. The shape of the PCL structures (dark areas, area size corresponds with the PCL content) seem to have something to do with 


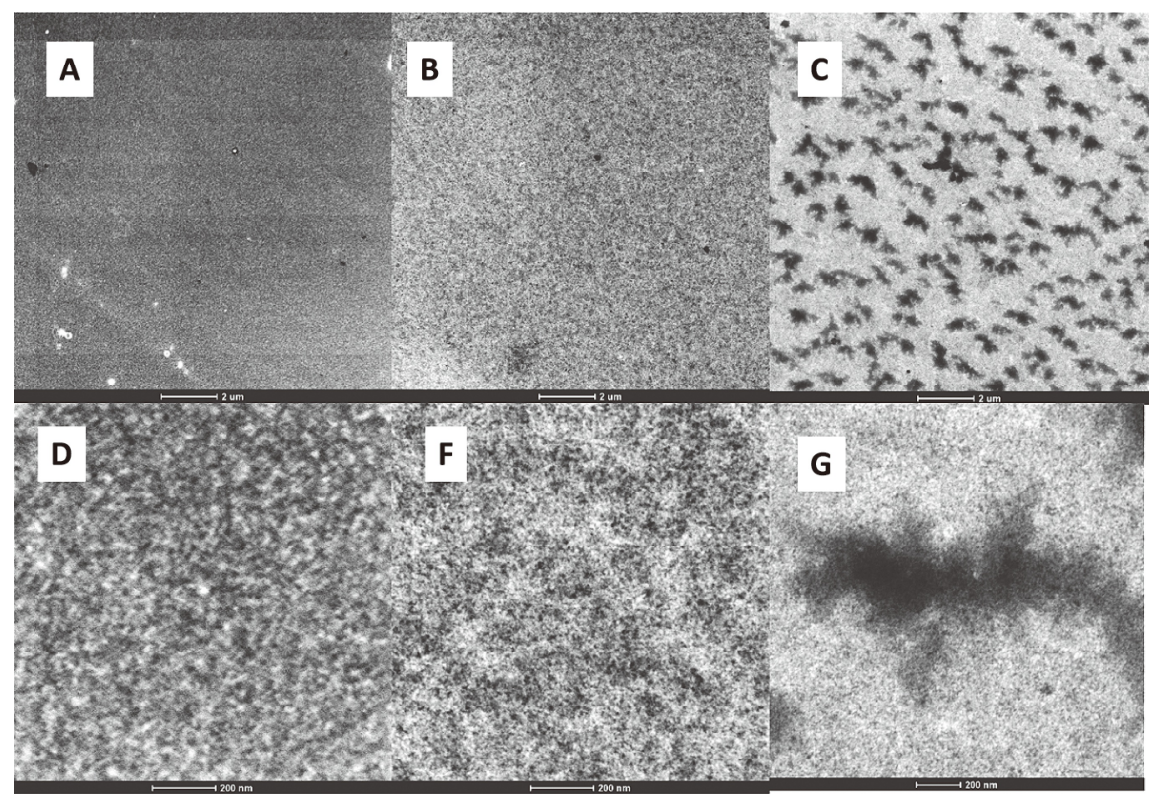

Fig. 5 STEM images obtained after staining with phosphoric tungstic acid of cured epoxy resins modified with 31 wt.- $\%$ of differently branched PCL. Left: $\mathrm{n}_{\mathrm{OH}}=16$, middle: $\mathrm{n}_{\mathrm{OH}}=4$ and right $\mathrm{n}_{\mathrm{OH}}=2$ in two different magnifications (scale bar of the upper row $2 \mu \mathrm{m}$ and of the lower row $200 \mathrm{~nm}$ ).

crystals but DSC as well as X-ray scattering shows that the polymers are amorphous. The images show that the size of the PCL structures decreases with increasing degree of branching. The size is in the range of $0.5 \mu \mathrm{m}$ for the samples containing PCL with $\mathrm{n}_{\mathrm{OH}}=2$ and in the lower $\mathrm{nm}$ range for the samples with $\mathrm{n}_{\mathrm{OH}}=4$ and 16. Qualitative observation indicates that the structures are even smaller for $\mathrm{n}_{\mathrm{OH}}=16$ compared to $\mathrm{n}_{\mathrm{OH}}=$ 4. For quantitative evaluation the pictures are not sufficient.

Tensile tests showed that yield strength increases with the degree of branching as long as network density is only reduced to a limited degree by the PCL modification. Therefore, we postulate that toughening is most pronounced if the domains in the epoxy network are as small as possible and that the morphology of the structures is between fully amorphous and crystalline.

\section{Conclusions}

The degree of branching together with the number of terminating $\mathrm{OH}$-groups of PCL can be adjusted by the use of start alcohols in PCL synthesis with the respective number of OH-groups. Melting and crystallization temperature decrease with the degree of branching as well as the degree of crystallization and branching does not influence crystallization kinetics. The PCL are integrated covalently by the activated monomer mechanism during cationic polymerization of an epoxy resin into the polymer network. STEM shows that nonspherical PCL rich domains are formed. The area on the images corresponds with the PCL amount in the polymer systems indicating almost complete phase separation during epoxide polymerization. Size of the domains decreases with increasing degree of PCL branching. Measurement of the tensile properties show that for a given PCL content the elongation at break as well as yield strength increases with increasing PCL branching and decreasing domain size, respectively. This shows a strong toughening effect. As reaction of the hydroxyl groups with the growing epoxy network reduces the network density and by this the glass transition temperature high amounts of hydroxyl groups lead to a decrease of yield strength together with a strong increase of elongation at break. As long as the glass transition temperature is well above the temperature during tensile test, toughening and not only softening of the polymers is observed. Following work will deal with decoupling of toughening and softening due to reduction of network density. In total the work shows that covalent integration of crystallizable polymer domains is a proper new method for epoxide toughening. The effect is most pronounced for domains as small as possible which size can be adjusted by the branching degree of the integrated polymer. 


\section{References}

1) A. Hartwig, Nachrichten aus der Chemie, 58, 523 (2010).

2) S. Sprenger, J. Appl. Polym. Sci. 130, 1421 (2013).

3) A. Hartwig, A. Luhring, J. Trautmann, Macromol. Mat. Eng,. 294, 363 (2009).

4) Y. Liu, J. Appl. Polym. Sci., 127, 3279 (2013).

5) Y. Yagci, W. Schnabel, Angew. Makromol. Chem., 270, 38 (1999).

6) E. Spyrou, Prog. Org. Coat., 43, 25 (2001).

7) S. Penczek, P. Kubisa, R. Szymanski, Makromol. Chem. Macromol. Symp., 3, 203 (1986).

8) A. Hartwig, K. Koschek, A. Lühring, O. Schorsch, Polymer, 44, 2853 (2003).

9) A. Hartwig, M. Sebald, Europ. Polym. J., 39, 1975 (2003).

10) H. Luitzen, P. Bitomsky, K. Rezwan, A. Hartwig, Europ. Polym. J., 49, 167 (2012).
11) H. Luitzen, T. M. Gesing, A. Hartwig, React. Funct. Polym., 73, 1038 (2013).

12) H. Luitzen, A. Hartwig, J. Adh. Sci. Technol., 27, 2531 (2013).

13) H. Lützen, T. M. Gesing, B. K. Kim, A. Hartwig, Polymer, 53, 6089 (2012).

14) K. Koschek, Composites A, 69, 21 (2015).

15) A. Bilgin, C. Yagci, Europ. Polym. J., 61, 240 (2014).

16) T. Endo, H. Uno, J. Polym. Sci.: Polym. Let. Ed., 23, 359 (1985).

17) M. Möller, R. Kange, J. L. Hedrick, J. Polym. Sci. A: Polym. Chem. 38, 2067 (2000).

18) C. J. Ong, F. P. Price, J. Polym. Sci.: Polym. Symp., 63, 45 (1978).

19) J. Choi, I.K. Kim, S.Y. Kwak, Polymer, 46, 9725 (2005).

20) A. S. Kasegaonkar, H. Barqawi, W. H. Binder, J. Polym. Sci. A: Polym. Chem., 53, 642 (2015). 